\title{
Perinatal nutrition programs neuroimmune function long-term: mechanisms and implications
}

\author{
Sarah J. Spencer* \\ School of Health Sciences and Health Innovations Research Institute, RMIT University, Melbourne, VIC, Australia
}

\section{Edited by:}

Jacob H. Hollis, Monash University,

Australia

Reviewed by:

Julie A. Chowen, Hospital Infantil

Universitario Niño Jesús, Spain

Anne-Simone Parent, Giga

Neurosciences, Belgium

*Correspondence:

Sarah J. Spencer, School of Health

Sciences and Health Innovations

Research Institute, RMIT University,

Building 223.2.14, Plenty Road,

Bundoora, Melbourne, VIC 3083,

Australia

e-mail: sarah.spencer@rmit.edu.au
Our early life nutritional environment can influence several aspects of physiology, including our propensity to become obese. There is now evidence to suggest perinatal diet can also independently influence development of our innate immune system. This review will address three not-necessarily-exclusive mechanisms by which perinatal nutrition can program neuroimmune function long-term: by predisposing the individual to obesity, by altering the gut microbiota, and by inducing epigenetic modifications that alter gene transcription throughout life.

Keywords: hypothalamic-pituitary-adrenal axis, obesity, glucorticoids, gut microbiota, epigenetics

\section{PERINATAL DIETARY INFLUENCE ON IMMUNE SYSTEM DEVELOPMENT}

The immune system of a newborn animal is relatively naïve and influences from the environment are necessary to allow it to become fully functional. Early exposure to pathogens develops an adaptive (Flajnik and Kasahara, 2010) and innate (Galic et al., 2009; Spencer et al., 2011) immunity that will facilitate appropriate responses to additional pathogens throughout life. However, there is now evidence that the early life diet is also crucial in programming long-term immune function.

\section{SPECIFIC NUTRIENTS IN PERINATAL DIET INFLUENCE IMMUNE SYSTEM DEVELOPMENT}

Specific nutrients within an individual diet can influence immune system development in different ways. Thus, antioxidants, oligosaccharides, polyunsaturated fatty acids (PUFAs), folate, and other vitamins have all been implicated in programming the developing immune system (West et al., 2010). For example, omega-3 PUFAs, those found in fish, fish oils, green plants, and some nuts and seeds (Huffman et al., 2011; Kremmyda et al., 2011), have an anti-inflammatory role. They inhibit cytokine production and may also alter gene expression and stimulate eicosanoid metabolism to control inflammation (Shek et al., 2012). Thus, a diet high in omega-3 PUFAs leads to a suppression of arachidonic acid-derived eicosanoids such as prostaglandin E2 (PGE2). PGE2 exerts pro-inflammatory effects and reduces the production of T helper type 1 (Th1) cytokines, such as interferon (IF) $\gamma$ and interleukin (IL)2 and enhances production of Th2 cytokines like IL-4 and IL-5. A shift in the Th1/Th2 balance toward a Th2-dominant profile is associated with impaired immune tolerance and allergies (Gottrand, 2008). High maternal intake of fish is thus associated with protection, in the infant, from allergic diseases such as eczema and asthma (Calvani et al., 2006; Romieu et al., 2007; Sausenthaler et al., 2007). Omega-6 PUFAs, those found in vegetable oils (Huffman et al., 2011; Kremmyda et al., 2011), are pro-inflammatory and may contribute to metabolic syndrome and cardiovascular disease (Patterson et al., 2012). A shift in the ratio of omega-3 to omega- 6 PUFA intake in the diet to favor omega- 6 encourages an allergenic Th2-dominant profile and is thus likely contributing to the recent increase in the incidence of childhood allergies (Shek et al., 2012). Folic acid is another example of a dietary component that influences immune development. Folic acid supplementation during pregnancy reduces the risk of neural tube defects and other congenital malformations (Wilcox et al., 2007), but it also predisposes infants toward allergies and immune dysfunction. For instance, folate supplementation in the first trimester of pregnancy predisposes infants to developing wheeze and respiratory infections in early life (Haberg et al., 2009).

\section{PERINATAL DIET INFLUENCES IMMUNE SYSTEM DEVELOPMENT THROUGH THE GUT MICROBIOTA}

One mechanism by which specific nutrients in the early life diet may be able to influence the adult immune system is by affecting the development, diversity, and function of the gut microbiota. In humans, the gastrointestinal tract is home to more than 100 trillion bacteria comprised of more than 1000 species (Qin et al., 2010). It also hosts numerous viruses, archaea, parasites, and fungi that together make up the gut microbiota (Ashida et al., 2012). This microbiota exists in a symbiotic relationship with its human hosts and can influence barrier function, trophic effects, metabolism, and the development of the adaptive and innate immune systems (Matamoros et al., 2013).

An adult's gut microbiome can be influenced by long-term changes in environmental factors. Hildebrandt and colleagues have shown 3 months of high fat diet (HFD)-feeding can influence a change in gut microbiota composition toward an increase in Firmicutes and Proteobacteria and a decrease in Bacteroidetes phyla in female mice (Hildebrandt et al., 2009). Although these changes were independent of obesity, other groups have shown 
a high fat, high sugar diet encourages increased adiposity and this phenotype can be transmitted to initially lean (normal diet) animals via transplantation of the microbiota (Turnbaugh et al., 2008). Most evidence, however, suggests the adult gut flora is very stable and short-term environmental influences in adulthood have limited effect (Wu et al., 2011). An infant, on the other hand, is not born with an established gut microbiome. Rather, the gut is colonized from bacteria in the environment in the first hours to days of life and the microbiome gains diversity and becomes stable and adult-like by around 3 years of age (Mackie et al., 1999; Palmer et al., 2007). In particular, an individual's diet during the early colonization phase can be tremendously important in determining the later composition of the gut microbiota.

Breast milk is a major source of the bacteria that colonize the gut (Martin et al., 2012). Breast-fed infants have higher counts of Bifidobacteria, Lactobacilli, and lower counts of Bacteroides, Clostridium coccoides group, Staphylococcus, and Enterobacteriaceae than formula-fed (Rinne et al., 2005; Fallani et al., 2010). Breast milk is also rich in oligosaccharides, which have a strong pre-biotic effect, promoting bacterial growth (Sela and Mills, 2010). Oligosaccharides found in human milk can improve the diversity of the microbiota, particularly promoting growth and metabolism of Bifidobacteria (Scholz-Ahrens et al., 2007). Human milk oligosaccharides can even improve glucose homeostasis (Laitinen et al., 2009). This interaction between breast milk oligosaccharides and gut bacteria also encourages immune system development and prevention of disease (Innis, 2007). Maternal diet strongly influences the composition of the breast milk and probably, therefore, the types of bacteria available to colonize the infant's gut. For instance, in rats, a maternal diet high in olive oil leads to high oleic-acid levels in the milk. A maternal diet high in PUFA is reflected in high PUFA concentrations in milk. Saturated fats are also transferred to the milk (Priego et al., 2013). When infants are introduced to a more complex diet at weaning there is a marked increase in Bacteroidetes, and a shift toward a more diverse colony (Koenig et al., 2011). The infant's post-weaning diet can therefore also affect the makeup of the gut microbiota. High dietary fat, for example, can cause a shift toward increased representation of Clostridium populeti bacteria and a reduction in Lactobacillus and Bacteroides species (Patrone et al., 2012). In weaned piglets the quantity and type of carbohydrate in the diet can influence the gut microbiota so that a diet high in hulled barley supplemented with beta-glucan encourages a Lactobacilli-dominant gut microbiota (Pieper et al., 2008).

Exactly what this means for the infant is yet unclear as there is no consensus as to what constitutes a "normal" gut microbiome (Matamoros et al., 2013). However, changing the makeup of the bacterial colony can certainly influence the immune system longterm. Infants given Bacteroides fragilis supplements early in life have high salivary secretory immunoglobulin A (IgA) and more basal IFN- $\gamma$ production. They also have reduced expression of the pathogen-associated molecular pattern receptor, toll-like receptor (TLR)4, mRNA and an attenuated pro-inflammatory response to stimulation with lipopolysaccharide (LPS) than those not given the B. fragilis supplements (Gronlund et al., 2000; Sjogren et al., 2009). These findings suggest the possibility that early colonization with $B$. fragilis can accelerate the maturation of the IgA system, leading to improved Th1/Th2 balance, a reduced likelihood of allergies developing, and a reduced response to LPS. A Lactobacilli-dominant colonization in infancy also reduces the likelihood the child will develop allergies by age five, while a Staphylococcus aureaus-dominant colonization has the opposite effect (Johansson et al., 2011). This latter bacterium has been linked to asthma and allergic rhinitis in childhood (Bjorksten et al., 2001). Lactobacillis tends to suppress numbers of interleukin (IL)-4, IL-10, and IFN- $\gamma$-secreting cells after stimulation with phytohaemagglutinin, whereas early life $S$. aureaus colonization has the opposite effect. Colonization with Lactobacilli also lowers cytokine responses to stimulation with an allergen (Martino et al., 2008). The Lactobacilli data suggest that this bacterium is able to suppress the immune response.

\section{PERINATAL DIET INFLUENCES IMMUNE SYSTEM DEVELOPMENT THROUGH EPIGENETIC MODIFICATIONS}

An interrelated mechanism by which perinatal diet can influence the innate immune system is through changes in the epigenome. Epigenetics refers to stable, heritable, environmentally-induced modifications to gene expression that occur independently of alterations to the DNA sequence (Christensen and Marsit, 2011). These modifications include changes in cytosine methylation, histone modification, and changes in non-coding RNAs such as microRNAs (Milagro et al., 2013). Together these mechanisms are responsible for regulating the degree of expression of a particular gene and the timing of its expression (Zeisel, 2009; McKay and Mathers, 2011). While epigenetic research is still a very young field, there is a large body of evidence accumulating to suggest diet, particularly in early life, can influence this epigenome long-term (Lillycrop et al., 2008). There are now data revealing almost every dietary component, from broccoli to betaine can influence the epigenome. Broccoli, for example contains sulforaphane, which induces histone modifications and has been implicated in preventing cancer (Dashwood and Ho, 2008; Delage and Dashwood, 2008; Nian et al., 2009). Betaine is found in grains and some vegetables and has been found to influence DNA methylation to promote fetal brain development (Sinclair et al., 2007; Mehedint et al., 2010; Zeisel, 2011).

Dietary components may also alter the epigenome to influence immune function, and there is a particular window of vulnerability for this during early development (West et al., 2011). Folate for example is a methyl donor. At least in mice, folate supplementation in pregnancy causes DNA hypermethylation, particularly in key metabolic genes (Waterland et al., 2008). Supplementation with methyl donors such as folate is also associated with altered immune function resulting in increased development of allergic asthma and eczema (Hollingsworth et al., 2008; Haberg et al., 2009). PUFAs also have the potential to cause epigenetic modifications. Crucially, PUFAs may be able to alter nuclear factor $\kappa \mathrm{B}(\mathrm{NF} \kappa \mathrm{B})$-mediated transcription of pro-inflammatory cytokines to influence the sensitivity of the immune response (Benatti et al., 2004; Waterland, 2006). NFкB is a transcription factor responsible for regulating the expression of more than 400 genes, including those responsible for pro-inflammatory cytokines, chemokines, and adhesion molecules (Vanden Berghe et al., 2006). NFKB-mediated transcription may be particularly 
vulnerable to early life influence and may be a principal mechanism by which epigenetic programming can influence immune system development long-term (Benatti et al., 2004; Vanden Berghe et al., 2006). NFKB itself is closely regulated by glucocorticoids and these are influenced by hypothalamic-pituitary-adrenal (HPA) axis activation (Sapolsky et al., 2000). Epigenetic programming by early life stress can result in changes in the methylation status of the glucocortiocoid receptor (GR) in the hippocampus and hypothalamus, altering negative feedback onto the hypothalamus, and thus HPA axis sensitivity (Liu et al., 1997; Weaver et al., 2004; Stevens et al., 2010; Begum et al., 2012). Early life diet can also impact HPA axis reactivity long-term (Boullu-Ciocca et al., 2005; Spencer and Tilbrook, 2009; Bulfin et al., 2011), altering the glucocorticoid response to stress. Enhanced circulating glucocorticoid levels in response to stress then feed back to inhibit NFKB-mediated cytokine production (Figure 1). The HPA axis in particular will be discussed in the next section.

\section{PERINATAL DIETARY INFLUENCE ON ADIPOSITY—LINKS TO IMMUNE SYSTEM DEVELOPMENT}

Dietary factors in early life clearly have a crucial influence on immune system development. The second half of this review will focus on how early life nutrition can program a pro-inflammatory basal immune profile by pre-disposing an individual to an obese phenotype.

Obesity is becoming a huge problem worldwide. In developed countries such as Australia and the US, 70-74\% of adult males and $56-64 \%$ of adult females are now either overweight or obese, with $28 \%$ of both classified as obese (BMI > 30). As many as $25-32 \%$ of Australian and US children are classified as overweight or obese (Cretikos et al., 2008; Nhanes, 2009-2010; AHS, 2011-2012).

\section{PERINATAL NUTRITION CAN PROGRAM ADULT WEIGHT AND METABOLISM LEADING TO ADIPOSE-DEPENDENT CHANGES IN IMMUNE FUNCTION}

Obesity itself, whether due to metabolic changes programmed in early life or to adult factors, is linked to changes in the inflammatory profile. It is now recognized that obesity is associated with, and may even be precipitated by, a chronic low-grade systemic and local inflammation (Gregor and Hotamisligil, 2011). This metabolic inflammation can contribute to insulin- and leptinresistance at various levels, including at the hypothalamus (Thaler and Schwartz, 2010).

Dietary factors such as PUFAs and glucose, as well as changes in the gut microbiota, are able to trigger a chronic low-grade inflammatory profile initially in white adipose tissue (WAT). This change is characterized by macrophage infiltration into WAT, apoptosis and necrosis of adipocytes, and reduced vascularity (Shu et al., 2012). These changes result in an abnormal preponderance of adipose-tissue macrophages, and these can make up almost $40 \%$ of the cells in obese adipose tissue (Weisberg et al., 2003; Xu et al., 2003). Adipose tissue macrophages, and potentially an increase in pattern recognition receptors on adipocytes themselves, lead to local inflammation with a predominance of pro-inflammatory over anti-inflammatory cytokines released (Shu et al., 2012). Hotamisligil and colleagues showed early
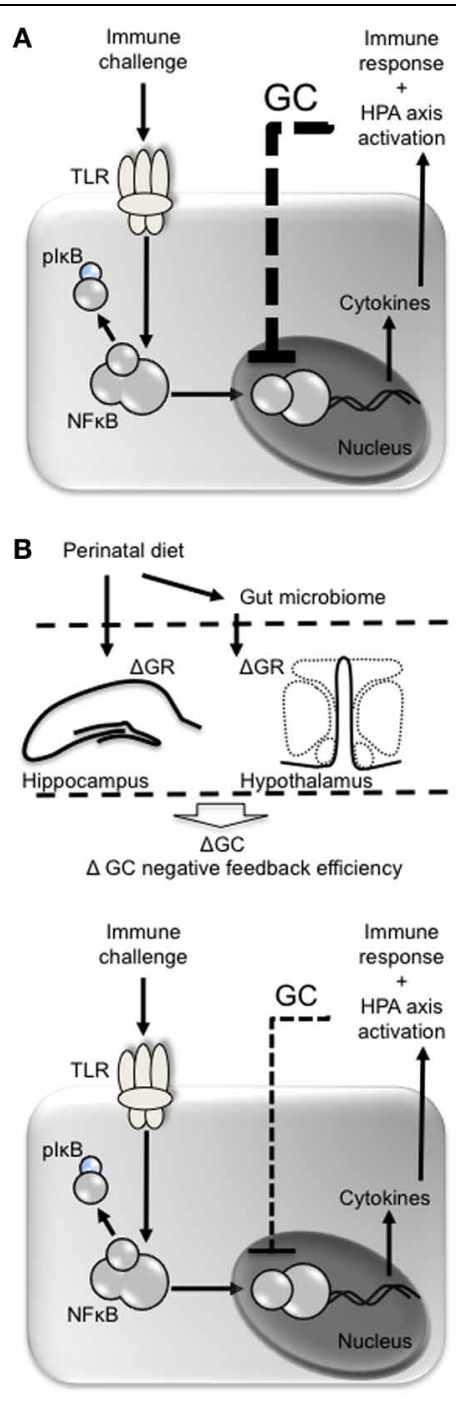

FIGURE 1 | Perinatal diet may influence glucocorticoid negative feedback following immune challenge. (A) Pathogens such as lipopolysaccharide act at toll-like receptors (e.g., TLR4) on immune cells leading to phosphorylation of inhibitory factor $(\mathrm{I})_{\kappa} \mathrm{B}$, releasing nuclear factor $(\mathrm{NF})_{\kappa} \mathrm{B}$ from its complex and allowing it to be translocated to the nucleus. $\mathrm{NK}_{\kappa} \mathrm{B}$ is responsible for the transcription of pro- and anti-inflammatory cytokines, the former of which stimulate the cyclo-oxygenase 2-mediated conversion of aracidonic acid into prostaglandins. Prostaglandins (e.g., PGE2) act at the brain to stimulate fever and sickness behavior and recruit the HPA axis. Once released, glucocorticoids (GC) negatively feed back to inhibit further NFkB-mediated transcription of cytokines. (B) The perinatal diet may influence glucocorticoid negative feedback by altering expression of glucocorticoid receptors (GR) in the hippocampus and hypothalamus leading to less efficient glucocorticoid-mediated inhibition of NFKB and an exacerbated immune response.

on there is a substantial increase in expression of the proinflammatory cytokine tumor necrosis factor (TNF) $\alpha$ in several rodent models of obesity and that neutralizing $\mathrm{TNF} \alpha$ could improve insulin-sensitivity in these animals (Hotamisligil et al., 1993, 1995; Uysal et al., 1997). The pro-inflammatory profile in the adipose leads to cytokine, adipokine, and fatty acid release 
into circulation, which have downstream effects on liver, muscle, and brain, and ultimately contribute to insulin-resistance (Shu et al., 2012).

As a result of these changes in the inflammatory profile, obese subjects have compromised immune function and are more likely to die from an acute infection than those of normal weight (Falagas and Kompoti, 2006). For instance, excessive body weight gain immediately postnatally predisposes infants to atopy and wheezing disorders (Pike et al., 2010). Obese patients in general are also twice as likely to die in intensive care due to infectionrelated complications as normal weight patients (Falagas and Kompoti, 2006).

It has been clear for some time that early life nutrition is able to program growth and can influence development of the central pathways subserving feeding and metabolism (Spencer, 2012). Babies born to overweight or obese mothers are significantly more likely to become overweight or obese themselves (Dabelea et al., 2000; Ruager-Martin et al., 2010), and babies born to mothers who ate a high fat, junk food diet while pregnant have higher levels of body fat when they are born, irrespective of whether or not the mothers were obese during pregnancy (Albuquerque et al., 2006; Srinivasan et al., 2006; Ashino et al., 2012). Associated with this excess body fat are indices of metabolic syndrome such as hyperinsulinemia and insulin resistance (Dabelea et al., 2000; Boney et al., 2005; Sewell et al., 2006; Catalano et al., 2009).

Paradoxically, babies that were undernourished in utero are also more likely to develop obesity and associated metabolic disorders (Spencer, 2012). In the first instance, in utero factors that cause the baby to be born small may also alter its metabolic pathways to encourage energy storage when food is available (Vickers et al., 2000, 2003; Bellinger et al., 2004; Bellinger and Langley-Evans, 2005). Secondly, preferred practise with small for gestational age babies is a program of intensive feeding to encourage appropriate brain and lung development (Lubchenco et al., 1972a,b; Brandt et al., 2003) and this catch up growth in the postnatal period also predisposes an individual to obesity (Ong et al., 2000, 2006; Brandt et al., 2003; Desai et al., 2005).

The importance of these findings is reflected in statistics showing overweight children are significantly more likely to be overweight adults than those of normal weight. As mentioned, excessive weight gain in the first week of life increases the longterm risk of obesity (Stettler et al., 2005). Furthermore, compared with children with a BMI below the 50th percentile, children between the 50 and 74th percentiles of BMI are approximately five times more likely to become overweight adults (Baird et al., 2005; Field et al., 2005; Druet et al., 2012).

\section{PERINATAL NUTRITION CAN PROGRAM CHANGES IN IMMUNE FUNCTION THAT ARE INDEPENDENT OF ADIPOSITY}

We can conclude from these studies there is an obvious connection between early life events programming an increased propensity to obesity and obesity itself resulting in a basal proinflammatory profile and susceptibility to infection. However, it is also apparent being overweight in early life can have independent and compounding effects on the inflammatory profile in adulthood.
Interesting evidence for the long-term effects of early life diet on the adult immune system comes from individuals who were undernourished in utero or as infants and did not develop obesity. Thus, a study of three rural villages in Gambia revealed subjects were significantly more likely to die of infectious disease in adulthood if they had been born during the nutritionally debilitating "hungry" season of July-December than during January-June when food was plentiful (Moore et al., 1999). A calorie restricted perinatal diet has also been shown to influence macrophage activation in adulthood so that adult rats undernourished during lactation had fewer alveolar macrophages and these released less nitric oxide in response to a fluoxetine challenge (Ferreira et al., 2009). Similarly, adult rats undernourished during lactation showed no change in immune parameters after an immune challenge either under control conditions or after being subjected to footshock, while control rats (normal diet during lactation) had elevated leukocyte counts and antibody titers (Barreto-Medeiros et al., 2007). These data suggest neonatal malnutrition can lead to a less reactive or less efficient immune response.

There is also some evidence that animals made obese as a result of perinatal diet can have changes in neuroimmune function in later life that are independent of the obesity per se. Several groups have now shown rats suckled in small litters, where they have greater access to the dam's milk, gain weight faster and maintain a higher body weight into adulthood (Plagemann et al., 1999; Schmidt et al., 2001; Morris et al., 2005; Rodel et al., 2008). We have shown these overweight rats, both males and females, have a significantly exacerbated neuroimmune response to LPS. This response is categorized by exacerbated $\mathrm{NF \kappa B}$ activation in the overweight rats, more circulating pro-inflammatory cytokines, and bigger fevers (Clarke et al., 2012).

Importantly, there are some fundamental differences between the changes in neuroimmune function in rats made overweight due to early life overfeeding and those in rats made overweight due to HFD-feeding in adulthood. Firstly, neonatally overfed rats do not have a profile of basal inflammation. There are no differences in basal circulating pro-inflammatory cytokine concentrations between those suckled in small litters (overweight) and those suckled in control litters (Clarke et al., 2012). As discussed above, several studies have shown human (Hak et al., 1999; Yudkin et al., 1999) and rodent (Hotamisligil et al., 1993) obese subjects have higher levels of circulating proinflammatory cytokines under unstimulated conditions, reflecting a pro-inflammatory profile. This difference may be a result of the degree of obesity, dietary composition, and/or that the perinatal overfeeding is able to prime the system to display an over-active response to immune challenge without affecting the basal inflammatory profile (Pohl et al., 2009).

The second key difference between immune dysfunction as a result of perinatal obesity and that of diet-induced obesity in adulthood is that perinatal obesity leads to an exacerbated immune response to a TLR4-mediated challenge, but not to a TLR3-mediated one (Clarke et al., 2012). The TLR family contains as many as 13 mammalian TLR, most of which respond to specific pathogen-associated molecular patterns. In the case of Gram negative bacteria, the pyrogenic moiety, LPS, interacts with cluster of differentiation (CD) 14 on the cell membrane, allowing 
MD2 to associate with TLR4. This interaction activates a myeloid differentiation primary response gene (MyD88)-dependent pathway, culminating in the phosphorylation of NFKB-interacting inhibitory factor (I) $\kappa B$, which releases NFkB from its complex. NFKB is then translocated to the nucleus of the cell where it stimulates the transcription of pro- and anti-inflammatory cytokines (Cartmell et al., 2003; Conti et al., 2004; Galic et al., 2009). Pro-inflammatory cytokines act at the brain to stimulate cyclo-oxygenase 2-mediated conversion of arachadonic acid into prostaglandins. These then act in the ventromedial preoptic area of the hypothalamus to disinhibit neuronal pathways that normally stimulate heat conservation, ultimately resulting in a regulated increase in body temperature; fever (Figure 1A) (Blatteis et al., 2000; Morrison et al., 2008). In the case of a virus, the viral double-stranded RNA interacts with TLR3 to stimulate the immune cascade via an interferon regulatory factor 3-dependent pathway. Polyinosinic:polycytidylic acid (PolyI:C) is a synthetic double-stranded RNA that mimics a virally-induced immune response and fever by activating TLR3. In neonatally overfed rats the response to LPS is exacerbated, while the response to PolyI:C remains normal (Clarke et al., 2012).

As with TLR4, there is increased TLR3 expression in neonatally overfed rat adipose tissue (Clarke et al., 2012). However, unlike in humans with adult-onset obesity (MMWR, 2009; Fuhrman et al., 2011) and adult HFD-fed rodents (Smith et al., 2007), the immune response to a TLR3 ligand is not altered in rats made obese due to neonatal overfeeding (Clarke et al., 2012). A possible explanation for differential effects on TLR4 and TLR3 signaling is in the receptor location, with TLR4 being membranebound and TLR3 internalized (Kumar et al., 2009; Konner and Bruning, 2011). Thus, although obesity in general may increase TLR3 expression, perinatally-induced obesity may not cause corresponding changes in transport of the ligand into the cell. For the patient, this may mean early-life programming of obesity may be associated with some form of protection against a viral infection in comparison with adult-onset obesity.

Perinatal overfeeding is, unlike adult onset obesity, also able to exacerbate immune responses independently of sickness behavior. Generally, an immune response elicits a variety of sickness behaviors in addition to the pro-inflammatory and febrile changes. These include anorexia, lethargy, depression, reduced activity, loss of libido (Dantzer and Kelley, 2007). Although there is a typical expression of sickness behavior with LPS in perinatally overfed rats, this is not exacerbated in these animals as the proinflammatory and febrile responses are (Clarke et al., 2012). In contrast, adult-onset obesity is strongly associated with an increase in sickness behavior relative to lean adults (Lawrence et al., 2012). Several aspects of sickness behavior are likely to be mediated centrally. For instance, leptin is a significant modulator of the anorexia associated with infection (Luheshi et al., 1999), and treatment with leptin anti-serum can reverse LPSinduced anorexia (Sachot et al., 2004; Harden et al., 2006). Leptin responses to LPS are similar in neonatally overfed and control rats despite pronounced differences in other cytokines, potentially facilitating similar sickness responses (Clarke et al., 2012).

It is yet unclear what this absence of an exacerbated sickness response after perinatal overfeeding would mean for a human subject. On one hand the subject is likely to be resilient to the feeling of sickness associated with an immune challenge, despite having exacerbated pro-inflammatory and febrile response, allowing them to continue life as normal when sick. On the other hand, sickness behavior is very important in promoting withdrawal so the body's resources are fully available to effectively combat the infection (Carlton et al., 2012).

\section{THE HYPOTHALAMIC-PITUITARY-ADRENAL AXIS}

As a possible key explanation for how the early life nutritional environment apparently programs adult immune function independently of obesity is in epigenetic changes to key aspects of the HPA axis. The HPA axis plays a significant modulatory role in the immune response with glucocorticoids acting to inhibit NFKB activation and downstream transcription of pro- and antiinflammatory cytokines (Figure 1) (Spencer et al., 2011). The HPA axis is also exceptionally sensitive to the early life environment. It has previously been established early life changes in HPA axis function are associated with changes in responses to LPS in adulthood. For instance, early life exposure to an immune challenge can permanently alter HPA axis function (Shanks et al., 1995, 2000; Hodgson et al., 2001). Early life immune challenge leads to an exacerbated HPA axis response to LPS in later life and blocking this increase with RU486 can restore a normal febrile response and cytokine profile (Ellis et al., 2005; Mouihate et al., 2010). At least some of the changes in HPA axis function that derive from early life events are linked to epigenetic modifications. For instance, rats that received high levels of care from their dams as pups (high levels of licking and grooming) have hypomethylation of the GR in the hippocampus and this is associated with increased hippocampal GR mRNA and a more efficient glucocorticoid negative feedback response to stress compared with rats that were given less attention as pups (Liu et al., 1997; Weaver et al., 2004). The hippocampal GR system plays a crucial role in glucocorticoid negative feedback regulation of the HPA axis, with glucocorticoids acting on GR at the hippocampus to inhibit PVN activation (De Kloet et al., 2009). As such, epigenetic modification of hippocampal GR may have significant effects on HPA axis function (Liu et al., 1997; Weaver et al., 2004; Mueller and Bale, 2006). Undoubtedly, glucocorticoid negative feedback at the hypothalamus itself is also important and can be altered by changes to the epigenome. For instance, maternal undernutrition is linked to increased histone acetylation and hypomethylation of the GR in the hypothalamus of the offspring, with a substantial increase in GR expression in this region. These modifications are closely linked with enhanced weight gain, and subsequent obesity, in these offspring (Stevens et al., 2010; Begum et al., 2012).

Early life diet is certainly capable of altering how the HPA axis functions. Females that become overweight as a result of early life overfeeding have enhanced PVN and corticosterone responses to acute stress (Spencer and Tilbrook, 2009). Conversely, males made lean by early underfeeding have more efficient HPA axis responses to stress, with reduced PVN neuronal activation and corticosterone responses that return to baseline more quickly (Bulfin et al., 2011). Neonatally overfed rats also have increased expression of the GR and increased glucocorticoid signaling in adipose tissue as adults (Boullu-Ciocca et al., 2005). In neonatally 
overfed rats, adult LPS leads to a significantly enhanced PVN response to stress and a corticosterone response that is significantly less efficient. Plasma corticosterone reaches a peak $30 \mathrm{~min}$ after LPS in control animals before returning to baseline, but in neonatally overfed rats the corticosterone levels still appears to be increasing after $90 \mathrm{~min}$ (Clarke et al., 2012). Together these data indicate early life overfeeding may lead to impaired development of central and peripheral HPA axis and glucocorticoid regulation resulting in altered HPA axis function in later life. These changes are likely to be responsible for a delay in the glucocorticoid response to an immune challenge, which would culminate in exacerbated PVN/HPA axis activation and a less effective glucocorticoid-mediated suppression of cytokine release, and fever (Figure 1).

\section{SEXUAL DIMORPHISM IN PERINATAL NUTRITIONAL PROGRAMMING OF IMMUNE FUNCTION}

Obesity can be manifested very differently in males and females. For instance, Australian and US statistics show a greater proportion of males than females are overweight or obese (Cretikos et al., 2008; Nhanes, 2009-2010; AHS, 2011-2012). Males are also more likely to accumulate visceral fat, a distribution that is more closely associated with complications such as heart disease (Bjorntorp, 1996). HPA axis responses to psychological stress also differ as a function of adiposity between males and females. Thus, perceived stress has been associated with greater increases in BMI in women, but not in men (Fowler-Brown et al., 2009), and female rats overfed as neonates have exacerbated HPA axis responses to restraint, while males do not (Spencer and Tilbrook, 2009). On the other hand, there is little evidence to suggest there are substantial sex differences in the neuroimmune response to an immune challenge in terms of how it is programmed by the perinatal environment. Most studies examining the effects of changes in gut flora on immune function have either only included males, or have found no effect of sex on immune-related outcomes (e.g., Calvani et al., 2006; Haberg et al., 2009; Patterson et al., 2012; Shek et al., 2012). There are some sex differences in the effects of gut flora on central nervous system circuitry. For example, hippocampal serotonin concentrations are elevated in male germ-free mice, but not females, compared with control mice with typical gut flora colonization (Clarke et al., 2013). However, immunological and neuroendocrine effects of changes to gut flora appear to be similar between males and females (Clarke et al., 2013). There has also been limited study on sex differences in epigenetic changes imposed by the early life environment. In humans, women have reduced global DNA methylation in peripheral blood compared with men, implying there may be differences in vulnerability to a challenge that influences methylation status (Zhang et al., 2011).

\section{REFERENCES}

AHS, (2011-2012). Australian Health Survey: First Results, Canberra: Australian Bureau of Statistics.

Albuquerque, K. T., Sardinha, F. L., Telles, M. M., Watanabe, R.

L., Nascimento, C. M., Tavares Do Carmo, M. G., et al. (2006). Intake of trans fatty acid-rich hydrogenated fat during pregnancy and lactation inhibits the hypophagic effect of central insulin in the adult offspring. Nutrition 22, 820-829. doi: 10.1016/j.nut.2006.04.009

Ashida, H., Ogawa, M., Kim, M., Mimuro, H., and Sasakawa, C. (2012). Bacteria and

However, methylation status of inflammatory markers such as IL-6 does not appear to be affected by sex (Zhang et al., 2012). Although there are sexually dimorphic effects of neonatal overfeeding on HPA axis responses to psychological stress (Spencer and Tilbrook, 2009), these do not seem to be apparent in the response to an immune challenge. As such, we have seen adult immune responses to LPS are exacerbated in both males and females made overweight due to neonatal overfeeding (Clarke et al., 2012). Thus, further work is necessary to clarify the differences, if there are any, between males and females in perinatal programming of neuroimmune function.

\section{SUMMARY AND FUTURE PERSPECTIVES}

Clearly, early life diet is essential for programming many aspects of adult physiology, including immune function and later susceptibility to disease. The gut microbiome and changes to the epigenetic profile may be particular mechanisms by which early life diet can alter immune function. In conjunction with these mechanisms, early life diet can predispose a subject to obesity, which has its own consequences for long-term immune function. Obesity that occurs as a result of early life diet may have independent implications for the immune system. Recent studies even imply that if one must become obese, there appear to be certain health advantages to doing it early on. At least, the basal pro-inflammatory profile, responses to a viral infection, and sickness behaviors seem to be unaffected in animals made obese by early life overfeeding, although febrile and cytokine responses to LPS are highly exacerbated. What this means for obese humans and for designing appropriate early life diets remains to be seen, but the implications for our immune systems are significant and clearly more work is needed in this field. Future research is needed to determine (1) how the early life gut microbiome can influence immune system development and if we can alter this with diet, (2) how early life influences, including diet, can cause epigenetic modifications to alter immune system development and if these can be reversed, and (3) how perinatal diet influences immune function independently of adult adiposity and if there is potential for early life interventions to reverse or ameliorate these effects.

\section{ACKNOWLEDGMENTS AND FUNDING SOURCES}

This work was supported by a Discovery Project Grant from the Australian Research Council (ARC) to Sarah J. Spencer (DP109339), and Project Grant from the National Health and Medical Research Council (NHMRC) to Dr Zane Andrews and Sarah J. Spencer (APP1011274). Sarah J. Spencer is an ARC Future Fellow (FT110100084) and an RMIT University VC Senior Research Fellow.

host interactions in the gut epithelial barrier. Nat. Chem. Biol. 8, 36-45. doi: 10.1038/ nchembio.741

Ashino, N. G., Saito, K. N., Souza, F. D., Nakutz, F. S., Roman, E. A., Velloso, L. A., et al. (2012). Maternal high-fat feeding through pregnancy and lactation predisposes mouse offspring to molecular insulin resistance and fatty liver. J. Nutr. Biochem. 23, 341-348. doi: 10.1016/j.jnutbio. 2010.12.011

Baird, J., Fisher, D., Lucas, P., Kleijnen, J., Roberts, H., and Law, C. (2005). Being big or growing fast: systematic review of size and growth in infancy and later obesity. $B M$ J 
331, 929. doi: 10.1136/bmj.38586. 411273.E0

Barreto-Medeiros, J., Queiros-Santos, A., Cabral-Filho, J. E., Ferreira, E. S. W. T., Leandro, C. G., Deiro, T. C., et al. (2007). Stress/aggressivenessinduced immune changes are altered in adult rats submitted to neonatal malnutrition. Neuroimmunomodulation 14, 229-334. doi: 10.1159/000112047

Begum, G., Stevens, A., Smith, E. B., Connor, K., Challis, J. R., Bloomfield, F., et al. (2012). Epigenetic changes in fetal hypothalamic energy regulating pathways are associated with maternal undernutrition and twinning. FASEB J. 26, 1694-1703. doi: 10.1096/fi.11-198762

Bellinger, L., and Langley-Evans, S. C. (2005). Fetal programming of appetite by exposure to a maternal low-protein diet in the rat. Clin. Sci. (Lond). 109, 413-420. doi: 10.1042/CS20050127

Bellinger, L., Lilley, C., and LangleyEvans, S. C. (2004). Prenatal exposure to a maternal low-protein diet programmes a preference for high-fat foods in the young adult rat. Br. J. Nutr. 92, 513-520. doi: 10.1079/BJN20041224

Benatti, P., Peluso, G., Nicolai, R., and Calvani, M. (2004). Polyunsaturated fatty acids: biochemical, nutritional and epigenetic properties. J. Am. Coll. Nutr. 23, 281-302. doi: 10.1080/07315724.2004.10719371

Bjorksten, B., Sepp, E., Julge, K., Voor, T., and Mikelsaar, M. (2001). Allergy development and the intestinal microflora during the first year of life. J. Allergy Clin. Immunol. 108, 516-520. doi: 10.1067/mai.2001.118130

Bjorntorp, P. (1996). The regulation of adipose tissue distribution in humans. Int. J. Obes. Relat. Metab. Disord. 20, 291-302.

Blatteis, C. M., Sehic, E., and Li, S. (2000). Pyrogen sensing and signaling: old views and new concepts. Clin. Infect. Dis. 31(Suppl. 5), S168-S177.

Boney, C. M., Verma, A., Tucker, R., and Vohr, B. R. (2005). Metabolic syndrome in childhood: association with birth weight, maternal obesity, and gestational diabetes mellitus. Pediatrics 115, e290-e296. doi: 10.1542/peds.2004-1808

Boullu-Ciocca, S., Dutour, A., Guillaume, V., Achard, V., Oliver, C., and Grino, M. (2005). Postnatal diet-induced obesity in rats upregulates systemic and adipose tissue glucocorticoid metabolism during development and in adulthood: its relationship with the metabolic syndrome. Diabetes 54, 197-203. doi: 10.2337/diabetes. 54.1.197

Brandt, I., Sticker, E. J., and Lentze, M. J. (2003). Catch-up growth of head circumference of very low birth weight, small for gestational age preterm infants and mental development to adulthood. J. Pediatr. 142, 463-468. doi: 10.1067/mpd.2003.149

Bulfin, L. J., Clarke, M. A., Buller, K. M., and Spencer, S. J. (2011). Anxiety and hypothalamicpituitary-adrenal axis responses to psychological stress are attenuated in male rats made lean by large litter rearing. Psychoneuroendocrinology 36, 1080-1091. doi: 10.1016/j. psyneuen.2011.01.006

Calvani, M., Alessandri, C., Sopo, S. M., Panetta, V., Pingitore, G., Tripodi, S., et al. (2006). Consumption of fish, butter and margarine during pregnancy and development of allergic sensitizations in the offspring: role of maternal atopy. Pediatr. Allergy Immunol. 17, 94-102. doi: 10.1111/j.1399-3038.2005.00367.x

Carlton, E. D., Demas, G. E., and French, S. S. (2012). Leptin, a neuroendocrine mediator of immune responses, inflammation, and sickness behaviors. Horm. Behav. 62, 272-279. doi: 10.1016/j.yhbeh.2012.04.010

Cartmell, T., Ball, C., Bristow, A. F., Mitchell, D., and Poole, S. (2003). Endogenous interleukin-10 is required for the defervescence of fever evoked by local lipopolysaccharideinduced and Staphylococcus aureus-induced inflammation in rats. J. Physiol. 549, 653-664. doi: 10.1113/jphysiol.2002.037291

Catalano, P. M., Presley, L., Minium, J., and Hauguel-De Mouzon, S. (2009). Fetuses of obese mothers develop insulin resistance in utero. Diabetes Care 32, 1076-1080. doi: $10.2337 / \mathrm{dc} 08-2077$

Christensen, B. C., and Marsit, C. J. (2011). Epigenomics in environmental health. Front. Genet. 2:84. doi: $10.3389 /$ fgene.2011.00084

Clarke, G., Grenham, S., Scully, P., Fitzgerald, P., Moloney, R. D., Shanahan, F., et al. (2013). The microbiome-gut-brain axis during early life regulates the hippocampal serotonergic system in a sex-dependent manner. Mol. Psychiatry 18, 666-673. doi: 10.1038/mp.2012.77
Clarke, M. A., Stefanidis, A., and Spencer, S. J. (2012). Postnatal overfeeding leads to obesity and exacerbated febrile responses to lipopolysaccharide throughout life. J. Neuroendocrinol. 24, 511-524.

Conti, B., Tabarean, I., Andrei, C., and Bartfai, T. (2004). Cytokines and fever. Front. Biosci. 9, 1433-1449. doi: $10.2741 / 1341$

Cretikos, M. A., Valenti, L., Britt, H. C., and Baur, L. A. (2008) General practice management of overweight and obesity in children and adolescents in Australia. Med. Care 46, 1163-1169. doi: 10.1097/MLR.0b013e318179259a

Dabelea, D., Hanson, R. L., Lindsay, R. S., Pettitt, D. J., Imperatore, G., Gabir, M. M., et al. (2000). Intrauterine exposure to diabetes conveys risks for type 2 diabetes and obesity: a study of discordant sibships. Diabetes 49, 2208-2211. doi: 10.2337/diabetes.49.12.2208

Dantzer, R., and Kelley, K. W. (2007). Twenty years of research on cytokine-induced sickness behavior. Brain Behav. Immun. 21, 153-160. doi: 10.1016/j.bbi.2006.09.006

Dashwood, R. H., and Ho, E. (2008). Dietary agents as histone deacetylase inhibitors: sulforaphane and structurally related isothiocyanates. Nutr. Rev. 66(Suppl. 1), S36-S38.

De Kloet, E. R., Fitzsimons, C. P., Datson, N. A., Meijer, O. C. and Vreugdenhil, E. (2009). Glucocorticoid signaling and stress-related limbic susceptibility pathway: about receptors, transcription machinery and microRNA. Brain Res. 1293, 129-141. doi 10.1016/j.brainres.2009.03.039

Delage, B., and Dashwood, R. H. (2008). Dietary manipulation of histone structure and function. Annu. Rev. Nutr. 28, 347-366. doi 10.1146/annurev.nutr.28.061807. 155354

Desai, M., Gayle, D., Babu, J., and Ross, M. G. (2005). Programmed obesity in intrauterine growthrestricted newborns: modulation by newborn nutrition. Am. J. Physiol. Regul. Integr. Comp. Physiol. 288, R91-R96.

Druet, C., Stettler, N., Sharp, S., Simmons, R. K., Cooper, C., Smith, G. D., et al. (2012). Prediction of childhood obesity by infancy weight gain: an individuallevel meta-analysis. Paediatr. Perinat. Epidemiol. 26, 19-26. doi: 10.1111/j.1365-3016.2011.01213.x

Ellis, S., Mouihate, A., and Pittman, Q. J. (2005). Early life immune challenge alters innate immune responses to lipopolysaccharide: implications for host defense as adults. FASEB J. 19, 1519-1521.

Falagas, M. E., and Kompoti, M. (2006). Obesity and infection. Lancet Infect. Dis. 6, 438-446. doi: 10.1016/S1473-309970523-0

Fallani, M., Young, D., Scott, J., Norin, E., Amarri, S., Adam, R., et al. (2010). Intestinal microbiota of 6-week-old infants across Europe: geographic influence beyond delivery mode, breastfeeding, and antibiotics. J. Pediatr. Gastroenterol. Nutr. 51, 77-84. doi: 10.1097/MPG.0b013e3181d1b11e

Ferreira, E. S. W. T., Galvao, B. A., Ferraz-Pereira, K. N., De-Castro, C. B., and Manhaes-De-Castro, R. (2009). Perinatal malnutrition programs sustained alterations in nitric oxide released by activated macrophages in response to fluoxetine in adult rats. Neuroimmunomodulation 16, 219-227. doi: 10.1159/000212382

Field, A. E., Cook, N. R., and Gillman, M. W. (2005). Weight status in childhood as a predictor of becoming overweight or hypertensive in early adulthood. Obes. Res. 13, 163-169. doi: 10.1038/oby.2005.21

Flajnik, M. F., and Kasahara, M. (2010). Origin and evolution of the adaptive immune system: genetic events and selective pressures. Nat. Rev. Genet. 11, 47-59. doi: 10.1038/nrg2703

Fowler-Brown, A. G., Bennett, G. G., Goodman, M. S., Wee, C. C., Corbie-Smith, G. M., and James, S. A. (2009). Psychosocial stress and 13-year bmi change among blacks: the pitt county study. Obesity (Silver Spring). doi: 10.1038/oby.2009.130

Fuhrman, C., Bonmarin, I., Bitar, D., Cardoso, T., Duport, N., Herida, M., et al. (2011). Adult intensivecare patients with 2009 pandemic influenza $\mathrm{A}(\mathrm{H} 1 \mathrm{~N} 1)$ infection. Epidemiol. Infect. 139, 1202-1209. doi: 10.1017/S0950268810002414

Galic, M. A., Spencer, S. J., Mouihate, A., and Pittman, Q. J. (2009). Postnatal programming of the innate immune response. Integr. Comp. Biol. 49, 237-245. doi: 10.1093/icb/icp025

Gottrand, F. (2008). Long-chain polyunsaturated fatty acids influence the immune system of infants. J. Nutr. 138, 1807S-1812S.

Gregor, M. F., and Hotamisligil, G. S. (2011). Inflammatory mechanisms in obesity. Аnnu. Rev. Immunol. 29, 415-445. doi: 10.1146/annurevimmunol-031210-101322

Gronlund, M. M., Arvilommi, H., Kero, P., Lehtonen, O. P., and Isolauri, 
E. (2000). Importance of intestinal colonisation in the maturation of humoral immunity in early infancy: a prospective follow up study of healthy infants aged 06 months. Arch. Dis. Child Fetal Neonatal Ed. 83, F186-F192. doi: 10.1136/fn.83.3.F186

Haberg, S. E., London, S. J., Stigum, H., Nafstad, P., and Nystad, W. (2009). Folic acid supplements in pregnancy and early childhood respiratory health. Arch. Dis. Child 94, 180-184. doi: 10.1136/adc.2008.142448

Hak, A. E., Stehouwer, C. D., Bots, M. L., Polderman, K. H., Schalkwijk, C. G., Westendorp, I. C., et al. (1999). Associations of C-reactive protein with measures of obesity, insulin resistance, and subclinical atherosclerosis in healthy, middleaged women. Arterioscler. Thromb. Vasc. Biol. 19, 1986-1991. doi: 10.1161/01.ATV.19.8.1986

Harden, L. M., Du Plessis, I., Poole, S., and Laburn, H. P. (2006). Interleukin-6 and leptin mediate lipopolysaccharide-induced fever and sickness behavior. Physiol. Behav. 89, 146-155. doi: 10.1016/j.physbeh.2006.05.016

Hildebrandt, M. A., Hoffmann, C., Sherrill-Mix, S. A., Keilbaugh, S. A., Hamady, M., Chen, Y. Y., et al. (2009). High-fat diet determines the composition of the murine gut microbiome independently of obesity. Gastroenterology 137, 1716-1724. e1-e2.

Hodgson, D. M., Knott, B., and Walker, F. R. (2001). Neonatal endotoxin exposure influences HPA responsivity and impairs tumor immunity in Fischer 344 rats in adulthood. Pediatr. Res. 50, 750-755. doi: 10.1203/00006450-20011200000020

Hollingsworth, J. W., Maruoka, S., Boon, K., Garantziotis, S., Li, Z., Tomfohr, J., et al. (2008). In utero supplementation with methyl donors enhances allergic airway disease in mice. J. Clin. Invest. 118, 3462-3469.

Hotamisligil, G. S., Arner, P., Caro, J. F., Atkinson, R. L., and Spiegelman, B. M. (1995). Increased adipose tissue expression of tumor necrosis factor-alpha in human obesity and insulin resistance. J. Clin. Invest. 95, 2409-2415. doi: 10.1172/ JCI117936

Hotamisligil, G. S., Shargill, N. S., and Spiegelman, B. M. (1993). Adipose expression of tumor necrosis factor-alpha: direct role in obesity-linked insulin resistance. Science 259, 87-91. doi: $10.1126 /$ science. 7678183
Huffman, S. L., Harika, R. K., Eilander, A., and Osendarp, S. J. (2011). Essential fats: how do they affect growth and development of infants and young children in developing countries? A literature review. Matern. Child Nutr. 7(Suppl. 3), 44-65. doi: 10.1111/j.1740-8709.2011.00356.x

Innis, S. M. (2007). Human milk: maternal dietary lipids and infant development. Proc. Nutr. Soc. 66, 397-404. doi: 10.1017/S0029665107005666

Johansson, M. A., Sjogren, Y. M. Persson, J. O., Nilsson, C., and Sverremark-Ekstrom, E. (2011). Early colonization with a group of Lactobacilli decreases the risk for allergy at five years of age despite allergic heredity. PLoS ONE 6:e23031. doi: 10.1371/journal.pone.0023031

Koenig, J. E., Spor, A., Scalfone, N., Fricker, A. D., Stombaugh, J., Knight, R., et al. (2011). Succession of microbial consortia in the developing infant gut microbiome. Proc. Natl. Acad. Sci. U.S.A. 108(Suppl. 1), 4578-4585. doi: 10.1073/pnas. 1000081107

Konner, A. C., and Bruning, J. C. (2011). Toll-like receptors: linking inflammation to metabolism. Trends Endocrinol. Metab. 22, 16-23. doi: 10.1016/j.tem.2010.08.007

Kremmyda, L. S., Vlachava, M., Noakes, P. S., Diaper, N. D., Miles, E. A., and Calder, P. C. (2011). Atopy risk in infants and children in relation to early exposure to fish, oily fish, or long-chain omega-3 fatty acids: a systematic review. Clin. Rev. Allergy Immunol. 41, 36-66. doi: 10.1007/s12016-009-8186-2

Kumar, H., Kawai, T., and Akira, S. (2009). Toll-like receptors and innate immunity. Biochem. Biophys. Res. Commun. 388, 621-625. doi: 10.1016/j.bbrc.2009. 08.062

Laitinen, K., Poussa, T., and Isolauri, E. (2009). Probiotics and dietary counselling contribute to glucose regulation during and after pregnancy: a randomised controlled trial. Br. J. Nutr. 101, 1679-1687. doi: 10.1017/S0007114508111461

Lawrence, C. B., Brough, D., and Knight, E. M. (2012). Obese mice exhibit an altered behavioural and inflammatory response to lipopolysaccharide. Dis. Model. Mech. 5, 649-659. doi: 10.1242/dmm.009068

Lillycrop, K. A., Phillips, E. S., Torrens, C., Hanson, M. A., Jackson, A. A., and Burdge, G. C. (2008). Feeding pregnant rats a protein-restricted diet persistently alters the methylation of specific cytosines in the hepatic PPAR alpha promoter of the offspring. Br. J. Nutr. 100, 278-282. doi: 10.1017/S0007114507894438

Liu, D., Diorio, J., Tannenbaum, B. Caldji, C., Francis, D., Freedman, A., et al. (1997). Maternal care, hippocampal glucocorticoid receptors, and hypothalamic-pituitaryadrenal responses to stress. Science 277, 1659-1662. doi: 10.1126/science.277.5332.1659

Lubchenco, L. O., DelivoriaPapadopoulos, M., Butterfield, L. J., Metcalf, D., Hix, I. E. Jr., et al. (1972a). Long-term follow-up studies of prematurely born infants. I. Relationship of handicaps to nursery routines. J. Pediatr. 80, 501-508.

Lubchenco, L. O., DelivoriaPapadopoulos, M., and Searls, D. (1972b). Long-term follow-up studies of prematurely born infants. II. Influence of birth weight and gestational age on sequelae. $J$. Pediatr. 80, 509-512.

Luheshi, G. N., Gardner, J. D. Rushforth, D. A., Loudon, A. S., and Rothwell, N. J. (1999). Leptin actions on food intake and body temperature are mediated by IL-1. Proc. Natl. Acad. Sci. U.S.A. 96, 7047-7052. doi 10.1073/pnas.96.12.7047

Mackie, R. I., Sghir, A., and Gaskins, H. R. (1999). Developmental microbial ecology of the neonatal gastrointestinal tract. Am. J. Clin. Nutr. 69 1035S-1045S.

Martin, V., Maldonado-Barragan, A., Moles, L., Rodriguez-Banos, M., Campo, R. D., Fernandez, L., et al. (2012). Sharing of bacterial strains between breast milk and infant feces. J. Hum. Lact. 28, 36-44. doi: 10.1177/0890334411424729

Martino, D. J., Currie, H., Taylor, A., Conway, P., and Prescott, S. L. (2008). Relationship between early intestinal colonization, mucosal immunoglobulin a production and systemic immune development. Clin. Exp. Allergy 38, 69-78.

Matamoros, S., Gras-Leguen, C., Le Vacon, F., Potel, G., and $\mathrm{De} \mathrm{La}$ Cochetiere, M. F. (2013). Development of intestinal microbiota in infants and its impact on health. Trends Microbiol. 21, 167-173. doi: 10.1016/j.tim.2012.12.001

McKay, J. A., and Mathers, J. C. (2011). Diet induced epigenetic changes and their implications for health. Acto Physiol. (Oxf) 202, 103-118. doi: 10.1111/j.1748-1716.2011.02278.x
Mehedint, M. G., Craciunescu, C. N., and Zeisel, S. H. (2010). Maternal dietary choline deficiency alters angiogenesis in fetal mouse hippocampus. Proc. Natl. Acad. Sci. U.S.A. 107, 12834-12839. doi: 10.1073/pnas.0914328107

Milagro, F. I., Mansego, M. L., De Miguel, C., and Martinez, J. A. (2013). Dietary factors, epigenetic modifications and obesity outcomes: progresses and perspectives. Mol. Aspects Med. 34, 782-812. doi: 10.1016/j.mam.2012.06.010

MMWR. (2009). Intensive-care patients with severe novel influenza A (H1N1) virus infection Michigan, June 2009. MMWR Morb. Mortal. Wkly. Rep. 58, 749-752.

Moore, S. E., Cole, T. J., Collinson, A. C., Poskitt, E. M., McGregor, I. A., and Prentice, A. M. (1999). Prenatal or early postnatal events predict infectious deaths in young adulthood in rural Africa. Int. J. Epidemiol. 28, 1088-1095. doi: 10.1093/ije/28.6.1088

Morris, M. J., Velkoska, E., and Cole, T. J. (2005). Central and peripheral contributions to obesity-associated hypertension: impact of early overnourishment. Exp. Physiol. 90, 697-702. doi: 10.1113/expphysiol.2005.030783

Morrison, S. F., Nakamura, K., and Madden, C. J. (2008). Central control of thermogenesis in mammals. Exp. Physiol. 93, 773-797. doi: 10.1113/expphysiol.2007.041848

Mouihate, A., Galic, M. A., Ellis, S. L., Spencer, S. J., Tsutsui, S., and Pittman, Q. J. (2010). Early life activation of toll-like receptor 4 reprograms neural anti-inflammatory pathways. J. Neurosci. 30, 7975-7983. doi: 10.1523/JNEUROSCI.6078-09.2010

Mueller, B. R., and Bale, T. L. (2006) Impact of prenatal stress on long term body weight is dependent on timing and maternal sensitivity. Physiol. Behav. 88, 605-614. doi: 10.1016/j.physbeh.2006.05.019

Nhanes. (2009-2010). National Health and Nutrition Examination Survey, Hyattsville, MD: Centres for Disease Control, National Center for Health Statistics.

Nian, H., Delage, B., Ho, E., and Dashwood, R. H. (2009). Modulation of histone deacetylase activity by dietary isothiocyanates and allyl sulfides: studies with sulforaphane and garlic organosulfur compounds. Environ. Mol. Mutagen. 50, 213-221. doi: 10.1002/em.20454

Ong, K. K., Ahmed, M. L., Emmett, P. M., Preece, M. A., and Dunger, 
D. B. (2000). Association between postnatal catch-up growth and obesity in childhood: prospective cohort study. BMJ 320, 967-971. doi: 10.1136/bmj.320.7240.967

Ong, K. K., Emmett, P. M., Noble, S., Ness, A., and Dunger, D. B. (2006). Dietary energy intake at the age of 4 months predicts postnatal weight gain and childhood body mass index. Pediatrics 117, e503-e508. doi: 10.1542/peds.20051668

Palmer, C., Bik, E. M., Digiulio, D. B., Relman, D. A., and Brown, P. O. (2007). Development of the human infant intestinal microbiota. PLoS Biol. 5:e177. doi: 10.1371/journal.pbio.0050177

Patrone, V., Ferrari, S., Lizier, M., Lucchini, F., Minuti, A., Tondelli, B., et al. (2012). Short-term modifications in the distal gut microbiota of weaning mice induced by a highfat diet. Microbiology 158, 983-992. doi: 10.1099/mic.0.054247-0

Patterson, E., Wall, R., Fitzgerald, G. F., Ross, R. P., and Stanton, C. (2012). Health implications of high dietary omega-6 polyunsaturated fatty acids. J. Nutr. Metab. 2012, 539426. doi: 10.1155/2012/539426

Pieper, R., Jha, R., Rossnagel, B., Van Kessel, A. G., Souffrant, W. B., and Leterme, P. (2008). Effect of barley and oat cultivars with different carbohydrate compositions on the intestinal bacterial communities in weaned piglets. FEMS Microbiol. Ecol. 66, 556-566. doi: 10.1111/j.1574-6941.2008.00605.x

Pike, K. C., Crozier, S. R., Lucas, J. S., Inskip, H. M., Robinson, S., Roberts, G., et al. (2010). Patterns of fetal and infant growth are related to atopy and wheezing disorders at age 3 years. Thorax 65, 1099-1106. doi: 10.1136/thx.2010.134742

Plagemann, A., Harder, T., Rake, A., Voits, M., Fink, H., Rohde, W., et al. (1999). Perinatal elevation of hypothalamic insulin, acquired malformation of hypothalamic galaninergic neurons, and syndrome $\mathrm{x}$-like alterations in adulthood of neonatally overfed rats. Brain Res. 836, 146-155. doi: 10.1016/S0006-899301662-5

Pohl, J., Woodside, B., and Luheshi, G. N. (2009). Changes in hypothalamically mediated acute-phase inflammatory responses to lipopolysaccharide in diet-induced obese rats. Endocrinology 150, 4901-4910. doi: 10.1210/en.2009-0526

Priego, T., Sanchez, J., Garcia, A. P., Palou, A., and Pico, C. (2013). Maternal dietary fat affects milk fatty acid profile and impacts on weight gain and thermogenic capacity of suckling rats. Lipids 48, 481-495. doi: 10.1007/s11745-0133764-3768

Qin, J., Li, R., Raes, J., Arumugam, M., Burgdorf, K. S., Manichanh, C., et al. (2010). A human gut microbial gene catalogue established by metagenomic sequencing. Nature 464, 59-65. doi: 10.1038 /nature 08821

Rinne, M., Kalliomaki, M., Arvilommi, H., Salminen, S., and Isolauri, E. (2005). Effect of probiotics and breastfeeding on the bifidobacterium and lactobacillus/enterococcus microbiota and humoral immune responses. J. Pediatr. 147, 186-191. doi: 10.1016/j.jpeds.2005.03.053

Rodel, H. G., Prager, G., Stefanski, V., Von Holst, D., and Hudson, R. (2008). Separating maternal and litter-size effects on early postnatal growth in two species of altricial small mammals. Physiol. Behav. 93, 826-834. doi: 10.1016/j.physbeh.2007.11.047

Romieu, I., Torrent, M., GarciaEsteban, R., Ferrer, C., Ribas-Fito, N., Anto, J. M., et al. (2007). Maternal fish intake during pregnancy and atopy and asthma in infancy. Clin. Exp. Allergy. 37, 518-525. doi: 10.1111/j.1365-2222.2007.02685.x

Ruager-Martin, R., Hyde, M. J., and Modi, N. (2010). Maternal obesity and infant outcomes. Early Hum. Dev. 86, 715-722. doi: 10.1016/j.earlhumdev.2010.08.007

Sachot, C., Poole, S., and Luheshi, G. N. (2004). Circulating leptin mediates lipopolysaccharideinduced anorexia and fever in rats. J. Physiol. 561, 263-272. doi: 10.1113/jphysiol.2004.074351

Sapolsky, R. M., Romero, L. M., and Munck, A. U. (2000). How do glucocorticoids influence stress responses. Integrating permissive, suppressive, stimulatory, and preparative actions. Endocr. Rev. 21, 55-89. doi: 10.1210/er.21.1.55

Sausenthaler, S., Koletzko, S., Schaaf, B., Lehmann, I., Borte, M., Herbarth, O., et al. (2007). Maternal diet during pregnancy in relation to eczema and allergic sensitization in the offspring at $2 \mathrm{y}$ of age. Am. J. Clin. Nutr. $85,530-537$.

Schmidt, I., Fritz, A., Scholch, C., Schneider, D., Simon, E., and Plagemann, A. (2001). The effect of leptin treatment on the development of obesity in overfed suckling Wistar rats. Int. J. Obes. Relat. Metab. Disord. 25, 1168-1174. doi: 10.1038/sj.ijo.0801669
Scholz-Ahrens, K. E., Ade, P., Marten, B., Weber, P., Timm, W., Acil, Y., et al. (2007). Prebiotics, probiotics, and synbiotics affect mineral absorption, bone mineral content, and bone structure. J. Nutr. 137, 838S-846S.

Sela, D. A., and Mills, D. A. (2010) Nursing our microbiota: molecular linkages between bifidobacteria and milk oligosaccharides. Trends Microbiol. 18, 298-307. doi 10.1016/j.tim.2010.03.008

Sewell, M. F., Huston-Presley, L., Super, D. M., and Catalano, P. (2006). Increased neonatal fat mass, not lean body mass, is associated with maternal obesity. Am. J. Obstet. Gynecol. 195, 1100-1103. doi: 10.1016/j.ajog.2006.06.014

Shanks, N., Larocque, S., and Meaney, M. J. (1995). Neonatal endotoxin exposure alters the development of the hypothalamic-pituitary-adrenal axis: early illness and later responsivity to stress. J. Neurosci. 15, 376-384.

Shanks, N., Windle, R. J., Perks, P. A., Harbuz, M. S., Jessop, D. S., Ingram, C. D., et al. (2000). Early-life exposure to endotoxin alters hypothalamic-pituitaryadrenal function and predisposition to inflammation. Proc. Natl. Acad. Sci. U.S.A 97, 5645-5650. doi: 10.1073/pnas.090571897

Shek, L. P., Chong, M. F., Lim, J. Y., Soh, S. E., and Chong, Y. S. (2012). Role of dietary long-chain polyunsaturated fatty acids in infant allergies and respiratory diseases. Clin. Dev. Immunol. 2012, 730568.

Shu, C. J., Benoist, C., and Mathis, D. (2012). The immune system's involvement in obesitydriven type 2 diabetes. Semin. Immunol. 24, 436-442. doi: 10.1016/j.smim.2012.12.001

Sinclair, K. D., Allegrucci, C., Singh, R., Gardner, D. S., Sebastian, S., Bispham, J., et al. (2007). DNA methylation, insulin resistance, and blood pressure in offspring determined by maternal periconceptional B vitamin and methionine status. Proc. Natl. Acad. Sci. U.S.A. 104, 19351-19356. doi: 10.1073/pnas.0707258104

Sjogren, Y. M., Tomicic, S., Lundberg, A., Bottcher, M. F., Bjorksten, B. Sverremark-Ekstrom, E., et al. (2009). Influence of early gut microbiota on the maturation of childhood mucosal and systemic immune responses. Clin. Exp. Allergy 39, 1842-1851. doi: 10.1111/j.1365-2222.2009.03326.x

Smith, A. G., Sheridan, P. A., Harp, J. B., and Beck, M. A. (2007).
Diet-induced obese mice have increased mortality and altered immune responses when infected with influenza virus. J. Nutr. 137, 1236-1243.

Spencer, S. J. (2012). Early life programming of obesity: the impact of the perinatal environment on the development of obesity and metabolic dysfunction in the offspring. Curr. Diabetes Rev. 8, 55-68. doi: $10.2174 / 157339912798829214$

Spencer, S. J., Galic, M. A., and Pittman, Q. J. (2011). Neonatal programming of innate immune function. Am. J. Physiol. Endocrinol. Metab. 300, E11-E18. doi: 10.1152/ajpendo.00516.2010

Spencer, S. J., and Tilbrook, A. (2009). Neonatal overfeeding alters adult anxiety and stress responsiveness. Psychoneuroendocrinology 34, 1133-1143. doi: 10.1016/j.psyneuen.2009.02.013

Srinivasan, M., Katewa, S. D., Palaniyappan, A., Pandya, J. D., and Patel, M. S. (2006). Maternal high-fat diet consumption results in fetal malprogramming predisposing to the onset of metabolic syndrome-like phenotype in adulthood. Am. J. Physiol. Endocrinol. Metab. 291, E792-E799. doi: 10.1152/ajpendo.00078.2006

Stettler, N., Stallings, V. A., Troxel, A. B., Zhao, J., Schinnar, R., Nelson, S. E., et al. (2005). Weight gain in the first week of life and overweight in adulthood: a cohort study of European American subjects fed infant formula. Circulation 111, 1897-1903. doi: 10.1161/01.CIR. 0000161797.67671.A7

Stevens, A., Begum, G., Cook, A., Connor, K., Rumball, C., Oliver, M., et al. (2010). Epigenetic changes in the hypothalamic proopiomelanocortin and glucocorticoid receptor genes in the ovine fetus after periconceptional undernutrition. Endocrinology 151, 3652-3664. doi: 10.1210/en.2010-0094

Thaler, J. P., and Schwartz, M. W. (2010). Minireview: Inflammation and obesity pathogenesis: the hypothalamus heats up. Endocrinology 151, 4109-4115. doi: 10.1210/en.2010-0336

Turnbaugh, P. J., Backhed, F., Fulton, L., and Gordon, J. I. (2008). Dietinduced obesity is linked to marked but reversible alterations in the mouse distal gut microbiome. Cell Host Microbe 3, 213-223. doi: 10.1016/j.chom.2008.02.015

Uysal, K. T., Wiesbrock, S. M., Marino, M. W., and Hotamisligil, G. S. (1997). Protection from obesityinduced insulin resistance in mice 
lacking TNF-alpha function. Nature 389, 610-614. doi: 10.1038/39335

Vanden Berghe, W., Ndlovu, M. N., Hoya-Arias, R., Dijsselbloem, N., Gerlo, S., and Haegeman, G. (2006). Keeping up NF-kappaB appearances: epigenetic control of immunity or inflammationtriggered epigenetics. Biochem. Pharmacol. 72, 1114-1131. doi: 10.1016/j.bcp.2006.07.012

Vickers, M. H., Breier, B. H., Cutfield, W. S., Hofman, P. L., and Gluckman, P. D. (2000). Fetal origins of hyperphagia, obesity, and hypertension and postnatal amplification by hypercaloric nutrition. Am. J. Physiol. Endocrinol. Metab. 279, E83-E87.

Vickers, M. H., Breier, B. H., McCarthy, D., and Gluckman, P. D. (2003). Sedentary behavior during postnatal life is determined by the prenatal environment and exacerbated by postnatal hypercaloric nutrition. Am. J. Physiol. Regul. Integr. Comp. Physiol. 285, R271-R273.

Waterland, R. A. (2006). Epigenetic mechanisms and gastrointestinal development. J. Pediatr. 149, S137-S142. doi: 10.1016/j.jpeds.2006.06.064

Waterland, R. A., Travisano, M., Tahiliani, K. G., Rached, M. T., and Mirza, S. (2008). Methyl donor supplementation prevents transgenerational amplification of obesity.
Int. J. Obes. (Lond). 32, 1373-1379. doi: 10.1038/ijo.2008.100

Weaver, I. C., Cervoni, N., Champagne, F. A., D'alessio, A. C., Sharma, S., Seckl, J. R., et al. (2004). Epigenetic programming by maternal behavior. Nat. Neurosci. 7, 847-854. doi: 10.1038/nn1276

Weisberg, S. P., McCann, D., Desai, M., Rosenbaum, M., Leibel, R. L., and Ferrante, A. W. Jr. (2003). Obesity is associated with macrophage accumulation in adipose tissue. J. Clin. Invest. 112, 1796-1808.

West, C. E., D'vaz, N., and Prescott, S. L. (2011). Dietary immunomodulatory factors in the development of immune tolerance. Curr. Allergy Asthma Rep. 11, 325-333. doi: 10.1007/s11882-011-0200-0

West, C. E., Videky, D. J., and Prescott, S. L. (2010). Role of diet in the development of immune tolerance in the context of allergic disease. Curr. Opin. Pediatr. 22, 635-641.

Wilcox, A. J., Lie, R. T., Solvoll, K., Taylor, J., McConnaughey, D. R., Abyholm, F., et al. (2007). Folic acid supplements and risk of facial clefts: national population based case-control study. BMJ 334, 464. doi: 10.1136/bmj.39079.618287.0B

Wu, G. D., Chen, J., Hoffmann, C., Bittinger, K., Chen, Y. Y., Keilbaugh, S. A., et al. (2011). Linking long-term dietary patterns with gut microbial enterotypes.
Science 334, 105-108. doi: 10.1126/science. 1208344

Xu, H., Barnes, G. T., Yang, Q., Tan, G., Yang, D., Chou, C. J., et al. (2003). Chronic inflammation in fat plays a crucial role in the development of obesity-related insulin resistance. J. Clin. Invest. 112, 1821-1830.

Yudkin, J. S., Stehouwer, C. D., Emeis, J. J., and Coppack, S. W. (1999). C-reactive protein in healthy subjects: associations with obesity, insulin resistance, and endothelial dysfunction: a potential role for cytokines originating from adipose tissue. Arterioscler. Thromb. Vasc. Biol. 19, 972-978.

Zeisel, S. H. (2009). Epigenetic mechanisms for nutrition determinants of later health outcomes. Am. $J$. Clin. Nutr. 89, 1488S-1493S. doi 10.3945/ajen.2009.27113B

Zeisel, S. H. (2011). Nutritional genomics: defining the dietary requirement and effects of choline. J. Nutr. 141, 531-534. doi: 10.3945/jn.110.130369

Zhang, F. F., Cardarelli, R., Carroll, J. Fulda, K. G., Kaur, M., Gonzalez, K. et al. (2011). Significant differences in global genomic DNA methylation by gender and race/ethnicity in peripheral blood. Epigenetics 6, 623-629. doi: 10.4161/epi.6.5 15335

Zhang, F. F., Santella, R. M., Wolff, M., Kappil, M. A., Markowitz, S. B., and Morabia, A. (2012).
White blood cell global methylation and IL-6 promoter methylation in association with diet and lifestyle risk factors in cancer-free population. Epigenetics 7, 606-614. doi: 10.4161/epi. 20236

Conflict of Interest Statement: The author declares that the research was conducted in the absence of any commercial or financial relationships that could be construed as a potential conflict of interest.

Received: 27 February 2013; accepted: 24 July 2013; published online: 12 August 2013.

Citation: Spencer SJ (2013) Perinatal nutrition programs neuroimmune function long-term: mechanisms and implications. Front. Neurosci. 7:144. doi 10.3389/fnins.2013.00144

This article was submitted to Frontiers in Neuroendocrine Science, a specialty of Frontiers in Neuroscience.

Copyright (C) 2013 Spencer. This is an open-access article distributed under the terms of the Creative Commons Attribution License (CC BY). The use, distribution or reproduction in other forums is permitted, provided the original author(s) or licensor are credited and that the original publication in this journal is cited, in accordance with accepted academic practice. No use, distribution or reproduction is permitted which does not comply with these terms. 